\title{
A Fabric Burn Hazard Protection Evaluation System
}

\author{
PAOLO CATALDI, PETER NEBOLSINE, JOHN MAGILL, WILLIAM LAUGHLIN, \\ and MICHAEL HINDS \\ Physical Sciences Inc. \\ Andover, MA 01810
}

\begin{abstract}
An innovative testing apparatus for military and civilian research and development and also quality assurance purposes has been developed for the U.S. Army Natick Soldiers Center to evaluate the burn hazard protection of clothing fabric samples. The system includes a closed-loop controlled IR radiant heat source simulating the radiant heat from remote fires that generates heat loads up to $100 \mathrm{~kW} / \mathrm{m}^{2}$ at the fabric sample, an automated shutter, a fabric sample holder, heat flux gage and skin simulant sensor, and a PC based data acquisition system with burn injury algorithms. Draping of clothing over the body is simulated by selecting various gaps between the fabric and sensor face from 0 to $65 \mathrm{~mm}$. Various selectable apparatus orientations of $0,30,45,60$, and 90 degrees address orientation specific convective effects. Results are presented documenting the overall performance of this innovative system. The radiant protective performance of a fabric is determined via the temporal temperature rise of a skin simulant sensor and heat flux sensor's output history. The automated data analysis algorithms output burn injury calculations, such as time to first degree burn and second degree burn, which are used in assessing the protective performance of fabrics.
\end{abstract}

KEYWORDS: flame testing, burn hazard evaluation, burn injury, closed-loop control

\section{NOMENCLATURE LISTING}

$\begin{array}{llll}C_{Q} & \text { photodiode calibration constant } & q & \text { heat flux, }\left(\mathrm{kW} / \mathrm{m}^{2}\right) \\ K_{i} & \text { integral gain } & t \text { time }(\mathrm{s}) \\ K_{P} & \text { proportional gain } & x \text { skin depth, } \mathrm{m} \\ K_{S} & \text { shutter calibration constant } & \text { Greek } \\ Q_{D} & \text { desired heat flux load, }\left(\mathrm{kW} / \mathrm{m}^{2}\right) & \Omega & \text { tissue damage integral } \\ Q_{F} & \text { heat flux at fabric sample, }\left(\mathrm{kW} / \mathrm{m}^{2}\right) & \alpha & \text { thermal diffusivity, } \mathrm{cm}^{2} / \mathrm{s} \\ V & \text { voltage, }(\mathrm{V}) & \tau & \text { Time } l a g,(\mathrm{~s}) \\ T & \text { temperature, }(\mathrm{K}) & \text { subscripts } \\ P & \text { pre-exponential burn factor } & 0 \text { Initial } \\ \Delta E / R & \text { exponential burn factor } & L \text { Lamp } \\ k & \text { thermal conductivity, }(\mathrm{W} / \mathrm{m} \mathrm{K}) & P D \quad \text { Photodiode }\end{array}$

\section{INTRODUCTION}

Flame and thermal hazards are a major threat to commercial and military personnel in the proximity of fires. Clothing provides personnel some protection from the burn hazards associated with radiant heat loads from fires and other thermal hazards. Understanding the flammability of fabrics on burn injury has been studied for years [1]. The burn hazard is a direct function of the radiative and convective heat flux history to the skin. The heat flux to the skin is dependent not only on the heat flux components to the clothing and the heat transfer characteristics of the clothing material, but also on the draping of the clothing over the skin [2], e.g., gap dimension, air flow, contact, etc. A number of test 
apparatuses and procedures to test the flame/thermal protective performance of fabrics have been developed through the years and have been adopted as standards. A comparison of several current methods to the Physical Sciences Inc. (PSI) system is shown in Table 1. The thermal protective test (TPP) [3] implements both convective and radiative heat loads on fabric and has been an established standard for years. The vertical flame test [4] is able to rate fabric samples but does not provide burn injury measurements. The fully clothed manikin tests [5] in large testing arenas are very inclusive but are complex and expensive in the procurement approval of fabrics. The PSI system is designed to simulate fabrics being in the proximity of fire and not necessarily immersed in a fire as simulated by the TPP system. Since the PSI system implements a radiation load only, it is not feasible to compare data with the TPP system where the fabric is immersed in a fire. There may be unique conditions where it may be comparable if the total heat load is identical but further studies would be needed to prove this. If flammable material is used in the PSI apparatus, it may also be applied to people whose clothing is accidentally ignited if the heat levels are high enough to ignite the fabric. The closed-loop control of the total heat load impinging on the fabric and general overall automation of the apparatus is an improved feature of the PSI system.

Table 1. Comparison of current thermal protection test methods.

\begin{tabular}{|l|c|c|c|c|}
\hline Characteristic & $\begin{array}{c}\text { TPP } \\
\text { Apparatus }\end{array}$ & $\begin{array}{c}\text { Vertical } \\
\text { Flame Test }\end{array}$ & $\begin{array}{c}\text { PyroMan Full } \\
\text { Scale Test }\end{array}$ & PSI System \\
\hline Standards & NFPA 1971 & $\begin{array}{c}\text { ASTM } \\
\text { D6413-99 }\end{array}$ & $\begin{array}{c}\text { ASTM } \\
\text { F1930-99 }\end{array}$ & \\
\hline Heat source & $\begin{array}{c}\text { radiant } \\
\text { heater and } \\
\text { burner }\end{array}$ & $\begin{array}{c}\text { tirrill or bunsen } \\
\text { burners }\end{array}$ & $\begin{array}{c}\text { propane } \\
\text { burners }\end{array}$ & $\begin{array}{c}\text { IR radiant } \\
\text { heater }\end{array}$ \\
\hline Heat flux - max & $84 \mathrm{~kW} / \mathrm{m}^{2}$ & open flame & $84 \mathrm{~kW} / \mathrm{m}^{2}$ & $100 \mathrm{~kW} / \mathrm{m}^{2}$ \\
\hline Heat sensors & $\begin{array}{c}\text { copper disk } \\
\text { calorimeter }\end{array}$ & none & skin simulant & $\begin{array}{c}\text { skin simulant } / \\
\text { heat flux gage }\end{array}$ \\
\hline Sample size & $\begin{array}{c}\text { fabric } \\
100 \mathrm{x} 100 \mathrm{~cm}\end{array}$ & $\begin{array}{c}\text { fabric } \\
7.6 \times 30.0 \mathrm{~cm}\end{array}$ & $\begin{array}{c}\text { clothing } \\
\text { ensemble }\end{array}$ & $\begin{array}{c}\text { fabric } \\
12.7 \times 17.8 \mathrm{~cm}\end{array}$ \\
\hline $\begin{array}{l}\text { Sample } \\
\text { orientation }\end{array}$ & horizontal & vertical & $\begin{array}{c}\text { dressed } \\
\text { manikin }\end{array}$ & $\begin{array}{c}0,30,45,60, \\
\text { \& } 90^{\circ}\end{array}$ \\
\hline $\begin{array}{l}\text { Properties } \\
\text { measured }\end{array}$ & $\begin{array}{c}\text { heat energy } \\
\text { from temp. }\end{array}$ & $\begin{array}{c}\text { char length, } \\
\text { afterglow time }\end{array}$ & $\begin{array}{c}\text { heat energy } \\
\text { from temp. }\end{array}$ & $\begin{array}{c}\text { heat flux \& } \\
\text { temperatures }\end{array}$ \\
\hline Burn injury & yes & no & yes & yes \\
\hline$\%$ burn injury & no & no & yes & exposure time \\
\hline $\begin{array}{l}\text { Burn injury } \\
\text { location }\end{array}$ & no & no & yes & $\begin{array}{c}\text { air gap } \\
\text { correlation }\end{array}$ \\
\hline Automation & no & no & no & yes \\
\hline
\end{tabular}

The authors have developed an innovative automated testing apparatus for military and civilian R\&D and also quality assurance purposes to evaluate the burn hazard protection provided by clothing fabric samples. The system includes a closed-loop controlled IR radiant heat source, an automated shutter, a fabric sample holder, heat flux gage and skin simulant sensor, and a PC based data acquisition system with burn injury algorithms. The automated computer controlled system allows the user to select via a graphical user interface the radiant heat flux level at the fabric sample, the irradiation time, and the gap 
between the fabric sample and whether a skin simulant sensor or heat flux gage output is used in the burn injury algorithm. Once the user has selected the input values and placed a fabric sample in the holder, the user starts the automated data acquisition sequence. The automated digital data acquisition system records the temporal data and provides graphical outputs during and after the experiment as well as automated archival storage. An automated green/red indicator on the computer screen display provides a pass/fail indication based on the burn injury being under or exceeding second degree burn injury level in virtually real time.

Design features have been incorporated for several different types of operation and users. The system will be readily used by researchers investigating the dependencies of calculated burn injury to a selectable range of heat flux values and irradiation times. Included in the system design is closed loop control of the heat flux. The user can select a variety of heat flux temporal profiles including top hat, linear ramp up, constant for a selectable time duration and then linear ramp down. The computer controlled shutter can be opened and closed at selected times during the temporal evolution of the heat flux. The sensor system provides flexibility to the user to calculate burn injury based on the output of a skin simulant sensor as well as determined via well known algorithms based on the output of a heat flux sensor. The temporal history of heat flux is used to calculate the temperature of skin at the basal layer. This temperature is then utilized in the omega integral to evaluate the level of burn injury [5]. Alternatively, the temperature from the skin simulant sensor can be used directly in the omega integral. The system allows the user to select which output is used to determine burn injury level.

The other projected use of the system is for quality assurance purposes. Since the system is automated, a relatively untrained person can operate the system based on stored parameters in the software. The user can operate the computer controlled system so that the same conditions can be repeated time after time. Comparisons can be made regarding the thermal injury levels for different fabric types/layups to the same temporal heat flux irradiations.

\section{CONCEPTUAL DESIGN}

The test apparatus assembly is shown in Fig. 1. The exit area of the heater is $12.7 \mathrm{x}$ $15.2 \mathrm{~cm}$ generating heat loads up to $100 \mathrm{~kW} / \mathrm{m}^{2}$ at $10 \mathrm{~cm}$ away from the heat source. A clear fused quartz commercial grade IR window provides protection of the lamp assemblies. The window is easily removed between tests allowing quick cleanup of buildup from charring fabric. A pneumatically operated dual-acting shutter is positioned directly below the window to provide accurate uniform heat loading during the desired exposure time.

The time for the shutters to fully open due to inertial effects and shutter opening time is measured to be less than 65 milliseconds. A transient heat analysis performed on the $1.25 \mathrm{~cm}$ thick Aluminum shutters revealed that less than $1 \%$ of the heat load emanating from the heat lamps would be re-radiated off the shutters. 


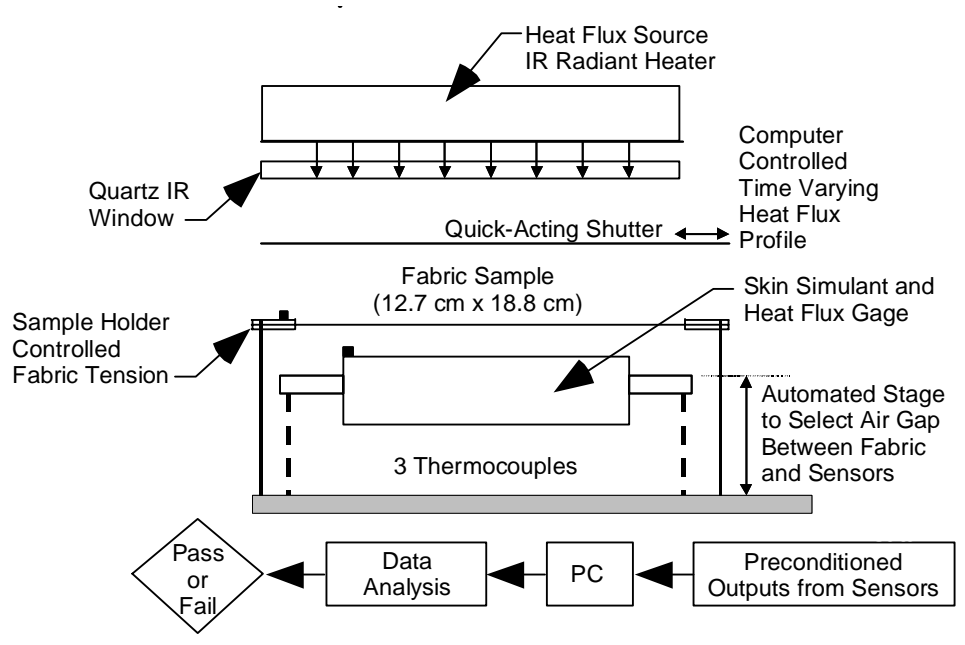

Fig. 1. Schematic of burn hazard evaluation system.

\section{Heat Lamp Control}

To ensure that a constant heat flux is provided from the heat lamps, a closed loop control system is used to adjust the input control level to the heat lamp controller based on the output level of the heat lamps compared to a predetermined desired level. The basic arrangement of the computer controlling the heat lamp output is shown in Fig. 2. An InGaAs photodiode with water cooling and $30 \mathrm{~dB}$ neutral density filter provides a measure of the lamp output, $V_{P D}$. It is placed just above the quartz window below the lamps to measure the relative level of radiant heat load from the lamps. A PC-based controller uses feedback to adjust this output level at 100 updates a second to achieve the desired heat load output. The computer based closed loop control system modifies the command voltage to the lamp controller, $V_{L}$, until the desired heat flux has been achieved.

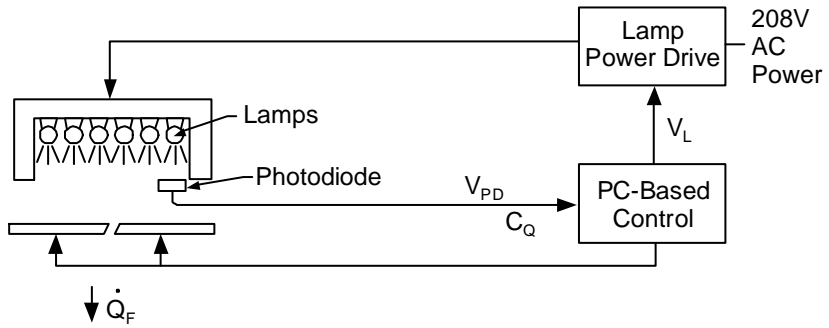

Fig. 2. Basic arrangement of computer controlling heat lamp output.

The command voltage to the lamp controller is calculated by the algorithm presented in Eq. 1. The first term in the equation relates the proportional difference between the desired heat level, $Q_{D}$, and the heat load impinging at the fabric location, $Q_{F}$. The second term represents the integrating effect of this difference throughout the experiment. Both of these terms are in addition to any prescribed initial voltage, $V_{o}$. The proportion, $K_{P}$, and integral gains, $K_{i}$, must be prescribed to manage the degree of control throughout the experiment. 
The heat load at the fabric location is calculated by measuring the photodiode voltage and applying calibration factors as shown in Eq. 2. The correlation between the photodiode voltages to the actual measured heat flux is expressed as $C_{Q}$ and is a linear function. A calibration factor, $K_{s}$, is required to account for different boundary conditions that occur within the lamp chamber while the shutter is in the closed position. Hence, when the shutter is closed, the heat lamps will be set to a level that normally would be considered too high, but when the shutter is opened, is correct.

$Q_{F}=K_{s} V_{P D} C_{Q}$

\section{Instrumentation}

A fabric sample holder has been designed to achieve consistent fabric configurations for each experiment. Below the fabric sample are two different sensors to determine the heat flux and potential for burn injury. The heat flux gage output voltage is proportional to the heat flux. In order to address the needs of experimenters who like to use a measurement system that has a temperature history comparable to that of human skin, a skin simulant gage is also provided. The skin simulant sensor is an off-the-shelf product with an embedded Type-T thermocouple sensor. The heat flux gage is considered to be the more reliable method of obtaining heat flux as it comes calibrated and can be easily recalibrated.

Certain safety features are also included in the system to provide a fail-safe system. The apparatus is enclosed in a polycarbonate chamber to protect any user failure resulting from either the heat lamps or the fast-acting shutter. Figure 3 displays the entire apparatus illustrating its orientation capabilities of $0,30,45,60$, and 90 degrees. A door interlock switch is mounted on the front door and an emergency push button switch is mounted to the front data acquisition panel as shown in Fig. 4. Since the switch cuts off signal to the heat lamp and shutters, the system can only operate with the doors in the closed position and the emergency switch enabled.

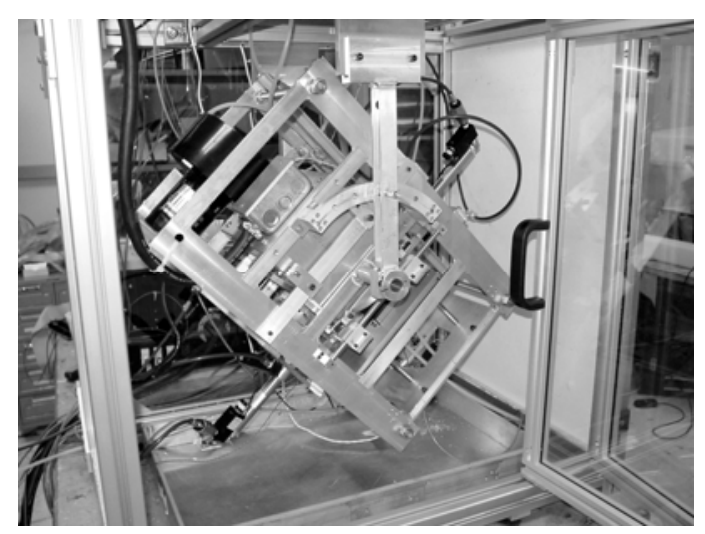

Fig. 3. A fabric burn hazard protection system. 


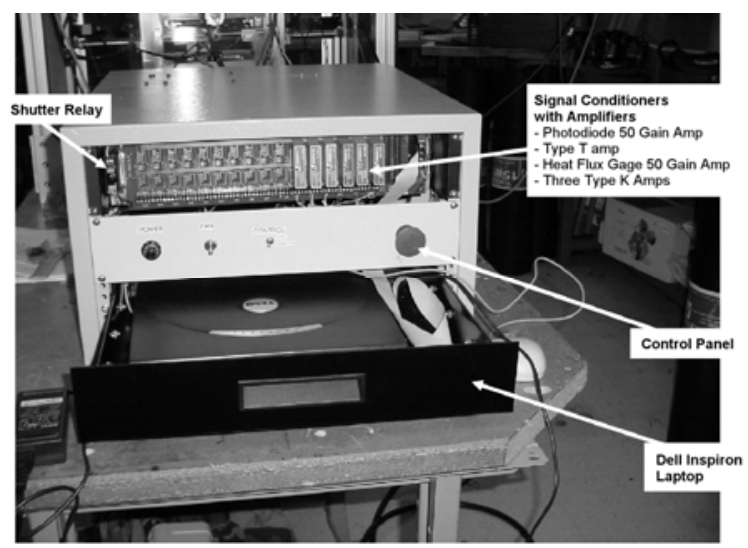

Fig. 4. Data acquisition rack for protection system.

\section{Software}

The user-friendliness of the burn hazard protection evaluation system is evident in the simple control of all the parameters in the graphical user interface (GUI) screens. An example of the primary screen used for controlling and real-time monitoring of the fundamental parameters of the experiment is shown in Fig. 5. The real-time operation of the feedback control loop is shown in the first curve along with the heat flux profile during the test. The real-time temperature profiles of the skin simulant sensor and each of the three, arbitrarily placed, Type K thermocouples are shown in the second curve. The desired heat level within the lamp's capabilities at any position away from the standard fabric location can be prescribed. The usefulness of this option may be evident when testing multiple fabrics where the reference location may change. The user may ensure a constant heat flux at the position of their choice for any desired fabric exposure time. The position between the fabric and thermal sensor system can be automatically varied by selecting the air gap dimension. The user can decide, via a pull-down menu, to calculate the burn injury based on the output of a skin simulant sensor as well as known algorithms based on the output of a heat flux sensor. An automated green/red indicator on the computer screen display provides a pass/fail indication based on the burn injury being under or exceeding second degree burn injury levels.

Other variables which may not vary between experiments are grouped on a secondary screen shown in Fig. 6. In this screen, the user can update acquisition parameters, proportional and integral control constants, photodiode, and heat transfer profile calibration constants. The details of the desired heat lamp profile including the rise and decay time as well as the time of shutter opening can also be specified. Finally, the user may select the type of $P$ and $\Delta E / R$ constants that are used in the burn injury model.

From a pull down menu, the user may select constants from Stoll [5], Tanaka [5], Henrique \& Moritz [6], and Mehta \& Wong [7]. The $\Omega$ integral criterion for triggering a pass/fail on the primary screen as well as the initial skin temperature used by the burn injury model is also required on the screen.

Automatic archiving of all variables is performed at the conclusion of the experiment. Plots of fundamental variables such as heat flux, skin simulant temperature, $\Omega$ integral, and views of both GUI screens are printed automatically for filing into a log book. 


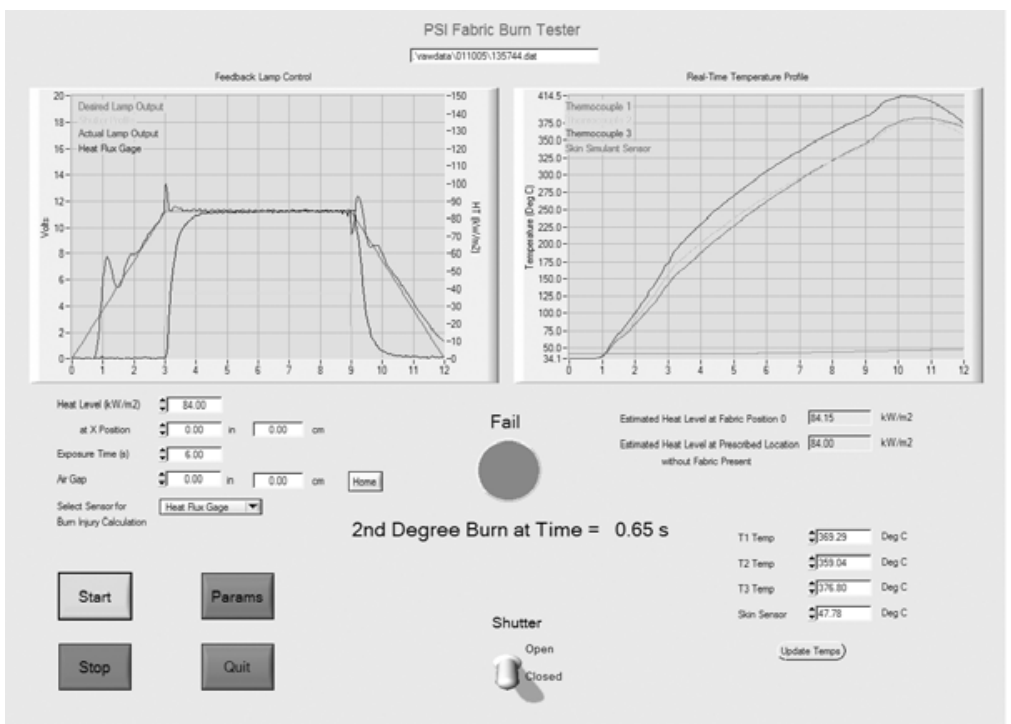

Fig. 5. Primary GUI screen for data acquisition.

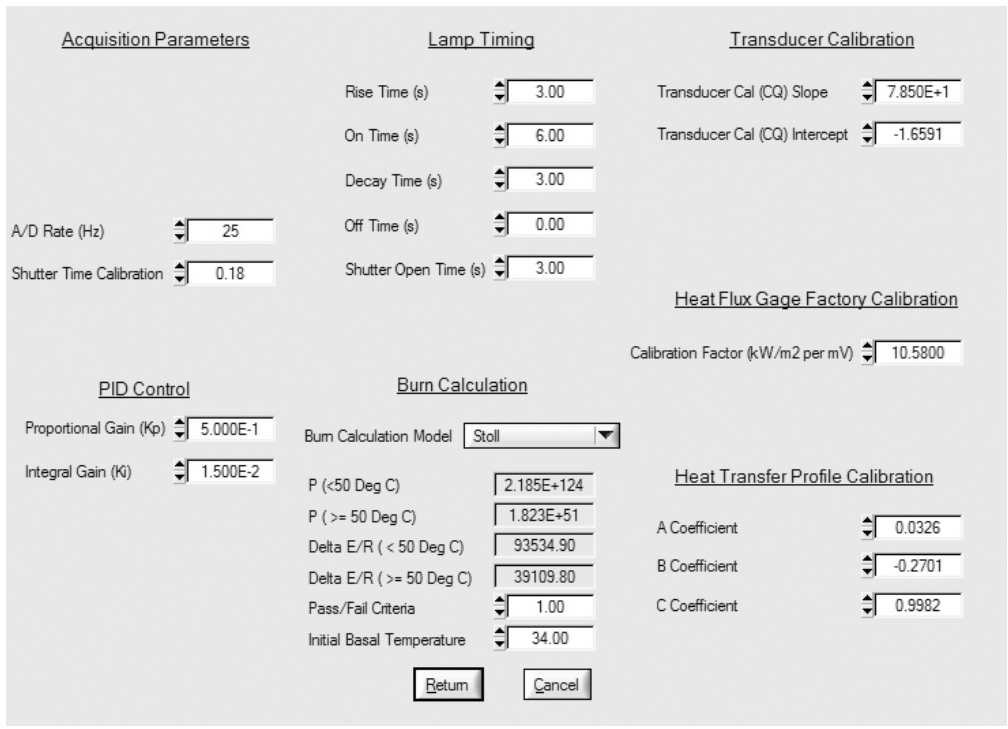

Fig. 6. Parameter GUI screen for data acquisition.

\section{Burn Injury Calculations}

The assessment of burn injury depends on the temporal profile of the thermal measurements, as well as a series of numerical calculations that take into account the thermal properties of skin and skin damage standards [5]. The basal layer is the interface between the epidermis and dermis layer. When the basal layer of the skin rises above $44^{\circ} \mathrm{C}$, the threshold of pain is exceeded and if heating continues the resulting burn is referred to superficial, or a first-degree burn. A second-degree burn is the criteria often 
used in the protective clothing industry to characterize the fire hazard protection provided by various types of clothing.

The following bullets summarize the necessary steps to turn thermal measurements into a burn injury model based on the tissue burn injury computer model annex of the ASTM Standard for flash fire testing using an instrumented manikin [5].

- Calculate/measure surface heat flux: The surface heat flux can either be measured or calculated. The measured heat flux is used as a surface condition in the skin heat transfer model.

- Calculate skin temperature history: Using a numerical heat transfer model, the temperature of the skin is calculated using the thermal physical properties of skin. A semi-infinite solution [8] shown in Eq. 3 is used to calculate the skin temperature at the basal layer based on the measured heat flux, $q$, at the skin surface. Since the solution represents a change in skin temperature, the initial temperature of the skin, $T_{o}$, is required in the calculation. The temperature at each time interval can be calculated for a skin depth of $80 \mu \mathrm{m}$ which represents the basal layer.

$$
T(x, t)=\frac{\sqrt{\alpha}}{k \sqrt{\pi}} \int_{0}^{t} q(t-\tau) e^{\left(-x^{2} / 4 \alpha \tau\right)} \frac{d \tau}{\sqrt{\tau}}+T_{o}
$$

An $\mathrm{ALGOR}^{\mathrm{TM}}$ finite-element model was generated for the transient heat conduction through all three layers of the skin to provide a tool for validating empirical relations used in the burn injury model. It was found that the Carslow and Jaeger model compares well to the finite-element transient conduction model.

- Determine burn injury: Skin damage is identified as being first, second, or third degree burn. A temperature of the basal layer raised above $44^{\circ} \mathrm{C}$ is necessary for damage to begin. At this temperature, irreversible damage begins to occur to the basal layer and the longer it is at or above this temperature, the greater the damage. The tissue damage integral [1] (i.e., $\Omega$ Integral) and the amount of burn damage determined by the value of $\Omega$ is shown in Eq. 4 . The total burn damage is found by integrating this equation over the time interval that the basal layer is above $44^{\circ} \mathrm{C}$.

$$
\Omega=\int_{0}^{t} P e^{-\Delta E / R T} d t
$$

$\begin{array}{ll}0<\Omega<0.5 & \text { No Damage } \\ 0.5<\Omega<1.0 & \text { First Degree Burn } \\ \Omega>1.0 & \text { Second Degree Burn }\end{array}$

The total damage to the skin can be applied to any depth of skin provided the appropriate values of $P$ and $\Delta E / R$ developed by Stoll and Tanaka [5]. 


\section{EXAMPLE RESULTS}

\section{Basic Performance of Heat Lamp Control}

The basic performance of the system is illustrated in Fig. 7. The user selects a desired heat lamp profile and the feedback control loop algorithm produces controlled radiant power levels. A linear ramp for desired heat lamp output is called for, but the nonlinear nature of the lamps, lamp controller and closed loop feedback control, has the response settle down to the intended behavior after slightly over 2 seconds. At 3 seconds, the shutter opens and the heat lamps output level is readjusted by the closed loop control system and the heat flux gauge output illustrates some finite response time, though the 1/e time constant is approximately 0.2 seconds. There are initial spikes upon opening and closing of the shutter which are quickly overcome by the controller. Hysteresis causes initial transients, but the controller quickly regulates power to the desired level of $84 \mathrm{~kW} / \mathrm{m}^{2}$. The shutter is commanded to close at 13 seconds and the decay time constant of the heat flux gauge is noticeable. The IR lamps are not turned off abruptly but are programmed to reduce in power to zero after three seconds after shutter closure. Proper correlation of the photodiode voltage to the heat flux at the fabric, $C_{Q}$, will yield desired heat flux. The photodiode is mounted at the periphery of the IR lamp housing. The linear relationship between photodiode output and heat flux is programmed into the closed loop control equation.

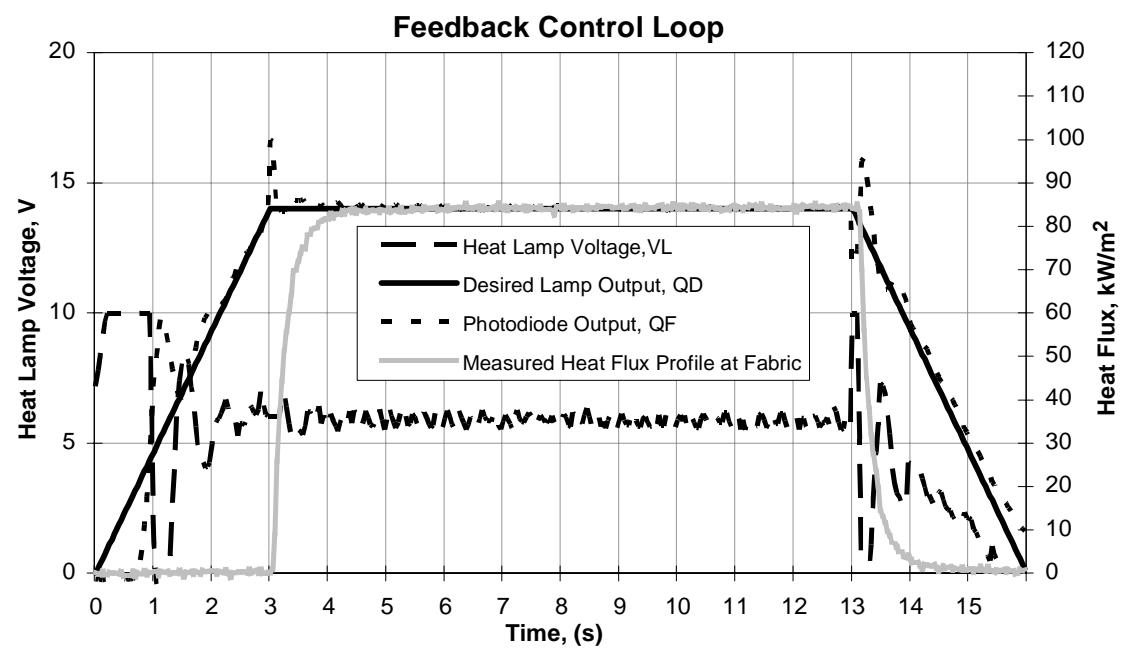

Fig. 7. Basic performance of heat lamp control.

\section{Heat Transfer Profiles, Characteristic Fabric Performance and Repeatability}

Example results will be now be discussed for the cases when no fabric is present and when a single layer of fabric is present. Repeatability could be demonstrated with the use of the control loop system and through the use of fabrics that were identical in texture and color. Darker colors within a fabric would char quicker than lighter colors within the same fabric and hence cause non-uniform heating of the fabric. Therefore, a majority of the testing was performed on standard green military textiles to demonstrate repeatability. Figure 8 illustrates the heat flux of $65 \mathrm{~kW} / \mathrm{m}^{2}$ when no fabric is present and the case for the same 
incident heat flux level, but now the heat flux $6.4 \mathrm{~mm}$ below the fabric is approximately $25 \%$ of the incident heat flux, illustrating the significant level of protection provided by the fabric. To illustrate repeatability, six tests were repeated at nominally the same test conditions of nominally $65 \mathrm{~kW} / \mathrm{m}^{2}$. The average of the six omega values is 2.02 with a standard deviation of 0.18 . In this case, the conditions to predict a second degree burn for these conditions have been exceeded.

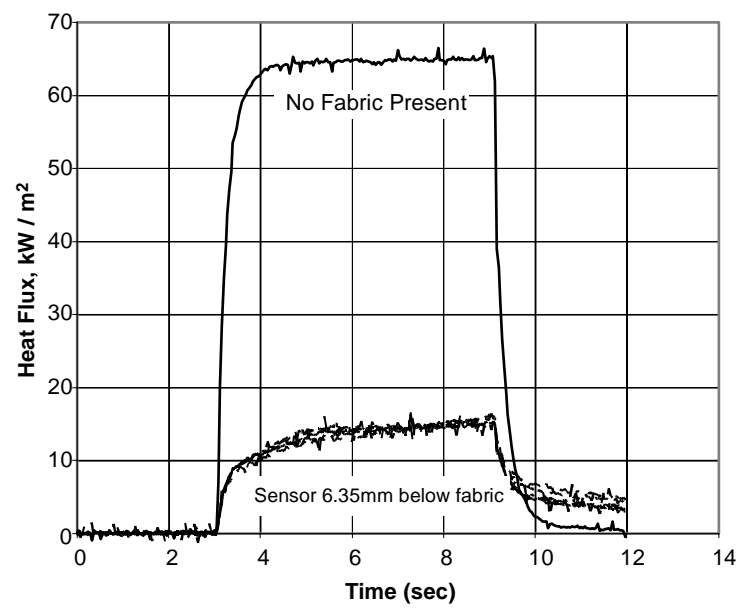

Fig. 8. Examples of heat flux sensor values versus time.

The presence of the fabric sample reduces the heat flux to approximately $25 \%$ of the incident heat flux value. The burn injury omega value of 2.1 results for this case indicating that a second degree burn would have occurred. Tests were performed at three different heat flux values: 84,75 , and $65 \mathrm{~kW} / \mathrm{m}^{2}$. The open shutter time was 6 seconds. The output of the heat flux gauge which was $6.4 \mathrm{~mm}$ below the same is shown in Fig. 9 along with the values of the omega integral for each heat flux condition. We note that already at $65 \mathrm{~kW} / \mathrm{m}^{2}$ a second degree burn would be anticipated.

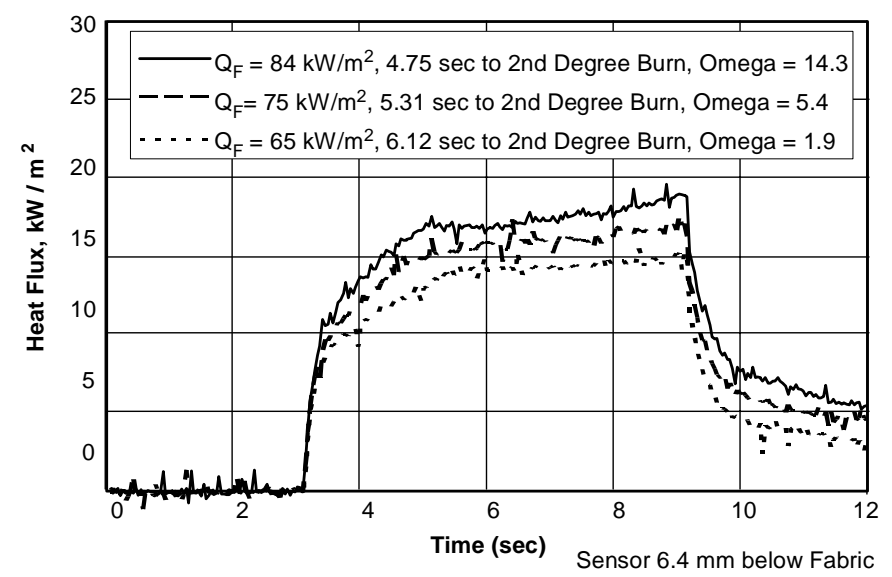

Fig. 9. Measured heat flux versus time for varying incident heat load. 
Tests were conducted with air gaps between the rear of the a single layer of fabric and the sensors of zero, $6.4 \mathrm{~mm}, 12.7 \mathrm{~mm}, 19 \mathrm{~mm}$, and $31.8 \mathrm{~mm}$. Figure 10 shows the result of the heat flux at those distances versus time for an incident heat flux value of $65 \mathrm{~kW} / \mathrm{m}^{2}$.

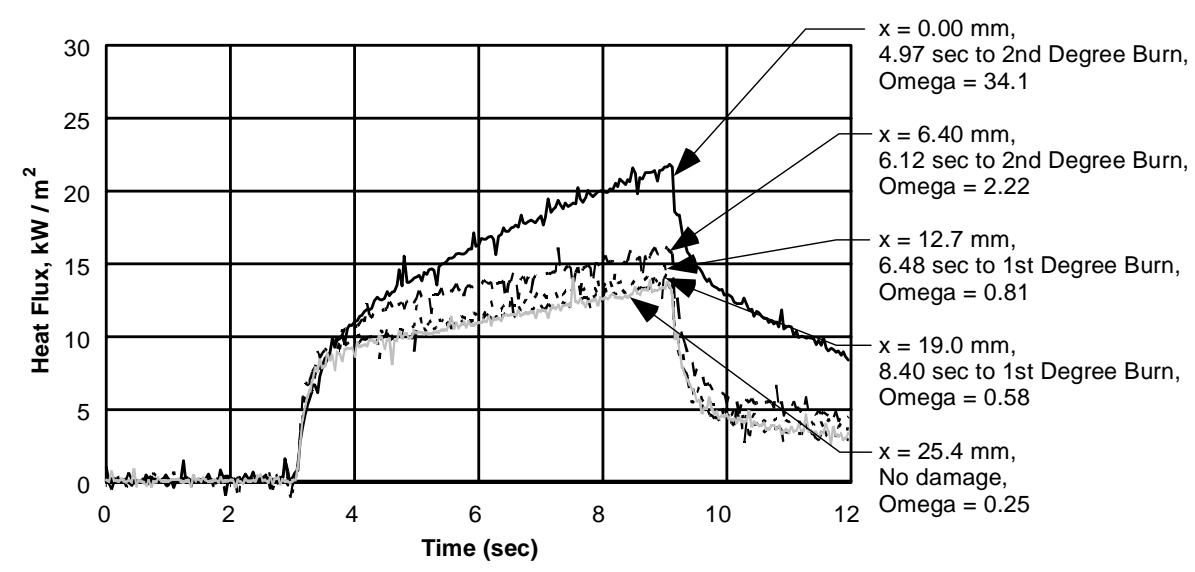

Fig. 10. Measured heat flux variation below fabric sample.

The shutter opens at 3 seconds and closes at 9 seconds. Also provided in Fig. 10 is the value of the omega integral for these air gaps. We note that for zero and $6.4 \mathrm{~mm}$, the threshold for predicting a second degree burn has been exceeded. On the other hand, for gaps of 12.7 and $19 \mathrm{~mm}$, a first degree burn is predicted, while when the gap was $31.8 \mathrm{~mm}$, only pain would be predicted. Burn injury predictions range from pain for a $31.8 \mathrm{~mm}$ gap to robust second degree burns for no gap or $6.4 \mathrm{~mm}$ gap. While first degree burns are predicted for 12.7 and $19 \mathrm{~mm}$ gaps.

The above examples illustrate the use of the system to make repeatable measurements for R\&D applications as well as for quality assurance purposes associated with the development, production and testing of fabrics.

\section{SUMMARY}

An innovative testing apparatus for military and civilian $R \& D$ and also quality assurance purposes has been developed to evaluate the burn hazard protection of clothing fabric samples. The system includes a closed-loop controlled IR radiant heat source, an automated shutter, a fabric sample holder, heat flux gage and skin simulant sensor, and a PC based data acquisition system with burn injury algorithms. Shutter open times as well as selectable temporal heat flux wave forms such as triangular and trapezoidal are readily programmed. Results have been presented documenting the overall performance of this innovative system. The radiant protective performance of a fabric/layup is determined via the temporal temperature rise of a skin simulant sensor or heat flux sensor's output history. The automated data analysis algorithms burn injury calculations, e.g., $\Omega$ integral and times to first degree burn and second degree burn, are used in assessing the protective performance of fabrics. The system has been designed for both research use by providing a user friendly graphical user interface that allows the wide selection of parameters for individual tests as well as repetitive use in quality assurance applications where pre-set testing conditions can be used repeatedly by minimally trained individuals. Data is automatically plotted and saved by the computer including a pass/fail performance based 
on a selectable criterion. This system is ready to be used for R\&D as well as quality assurance applications.

\section{ACKNOWLEDGEMENTS}

The authors would like to acknowledge the financial support for this work from the U.S. Army under contract DAAD16-02-C-0002 as well as the support and guidance from Dr. Calvin Lee and also Mr. Il Young Kim, of the U.S. Army.

\section{REFERENCES}

[1] Backer, S., Tesoro, G.C., Toong, T.Y., and Moussa, N.A., Textile Fabric Flammability, Cambridge Mass and London, UK, MIT press, 1976.

[2] Kim, I.Y., Lee, C., Li, P., Corner, B., and Paquette, S., "Investigation of Air Gaps Entrapped in Protective Clothing Systems," Fire and Materials, 2002, Vol. 26, pp. 121-126.

[3] National Fire Protection Association, NFPA 1971, Protective Ensemble for Structural Fire Fighting, p. 40-44.

[4] "Standard Test Method for Flame Resistance of Textiles (Vertical Test)," ASTM Committee D-13 Textiles, Designation: D6413-99.

[5] "Standard Test Method for Evaluation of Flame Resistant Clothing for Protection Against Flash Fire Simulation Using an Instrumented Manikin," ASTM Committee F-23 on Protective Clothing, Designation: F1930-99.

[6] Henrique, F.C. and Moritz, A.R., "Studies of Thermal Injury I: The Conduction of Heat to and Through Skin and the Temperatures Attained Therein. A Theoretical and Experimental Investigation," American Journal of Pathology, Vol. 23, 1947, p 531.

[7] Morse, H., Tickner, G., and Brown, R., "Burn Damage and Burn Depth Criteria," Aerotherm Projects 6269 and 6393, Aerotherm TN-75-26, 1975.

[8] Carslaw, H.S. and Jaeger, J.C., "Conduction of Heat in Solids," Clarendon Press, $2^{\text {nd }}$ Edition, 1986. 